\title{
Editorial
}

\section{Management and high technology}

\begin{abstract}
'What is the most important cause of the failure experienced by small businesses in the U.S. in the use of management information systems which we could learn to avoid?' This was one of the most frequently asked questions I encountered during a three-week tour of lectures on computer information systems in China in June 1984. The audiences consisted of faculties and students in the school of business, management science, computer sciences and fields of computer applications and representatives from industry. They were up-to-date and somewhat experienced in the use of data base technologies and decision support systems. The use of computers for simulation, fourth generation languages and beyond, and the fusion of computers and communications were less familiar. Most unfamiliar, however, was the recognition that proper management of the development and use of high technologies was the major factor in success. Nor was the potential impact of successful high technologies on management fully appreciated.
\end{abstract}

Hans Gottinger has already written in this forum about the need to consider the social impact of high technology (HSM 4, Spring 1984). The message about the importance of management for ensuring net benefits from the introduction of high technology into human systems is only now being broadcast and to some extent heeded in developed countries. The challenge to management is that there are many human systems that are affected by technology. This requires new perspectives and a reorientation that gives top priority to the needs of the end-users of technology and to the integration of various systems toward this end. Just as industry leaders try to shape policies that shift the emphasis away from 'management with financial mirrors' - mergers, investments driven by tax considerations, treating labor as a discardable commodity - toward real productivity-improving gen-

North-Holland

Human Systems Management 5 (1985) 183-184 eration of goods and services, so managers responsible for shaping the relations between high technology and management are shifting concern from the 'how to' to the 'what' of decision-making. The goals of management as it grapples with the high-technology challenge are more visibly part of a manager's agenda. We are seeing more stress on the quality of decisions and on the efficiency and effectiveness of technology-supported decision-making processes.

'We need leadership, not management', is heard with increasing frequency. This refers particularly to management taught as if it were a science, and excesses of which - overanalyticity, overreliance on product surveys, risk aversion - are often blamed for productivity declines. Leadership means three things: (1) (a) clear vision of a valuable goal, product or service to be accomplished, (b) presented enthusiastically so as to stimulate, motivate and persuade a (c) critical set of persons who can bring it about. (2) Adaptiveness to changing conditions or to fixed conditions as more is known about them, with the ability to flexibly adjust and to learn from correctible mistakes. (3) The political will, economic resources and know-how to get results.

In this regard, there is great variability among institutions and individuals in China, as there is elsewhere. The mark of maturity in the development or use of high technology is the awareness of its connection to leadership. There is a need for answers to such questions as: What can we succeed in accomplishing with the help of high technology that we did not think of trying or could not do without it? Do we, from a human perspective, really want to accomplish what we could do best? How can we bring about the development of man-machine systems that enable us to better achieve our most valued goals, or to do so more efficiently? Can we assure that the means of attaining these ends will also reflect basic human values? How will use of high technology further a 
leader's self-interest; how can he manage the technology to ensure the result is in his interest, and under what conditions will such pursuits of self-interest be consonant with basic human values?

Human Systems Management seeks to fill the niche for a scholarly forum for the exchange of new cases, methods, evidence, and justified insights about how to improve productivity, human resource development, and man-machine interaction in ways that enable managers in institutions to better achieve our most valued goals. What unites the diverse managerial, technological and scientific communities and the different sociotechnological systems they administer or advise are the human values that they may come to realize as something they have in common and feel most strongly about. This kind of systems thinking goes beyond intradisciplinary professional camaraderie, but need not-indeed should not-fail to be grounded in pragmatic managerial experience, problems and aids. As Confucius said in the dawn of Chinese civilization, codifying a complex system of traditions to sustain the world's oldest culture, it is Man who can make the System great - not the System which makes Man great. The Chinese managers of the information systems function in their burgeoning industries gave evidence of recognizing the demands of the high-technology environment all modern enterprises confront, as well as respect for their ancestral values. As high technology pervades all aspects of life everywhere, it is essential that our leaders recognize their responsibility for shaping the way it changes our lifestyle before technological imperatives, through their own momenta, impose such change upon us.

Manfred KOCHEN 